\title{
Article
}

\section{COVID-19 Pandemic and Upcoming Influenza Season-Does an Expert's Computed Tomography Assessment Differentially Identify COVID-19, Influenza and Pneumonias of Other Origin?}

\author{
Johannes Rueckel ${ }^{1, *,+}{ }^{+}$Nicola Fink ${ }^{1,2,+}{ }^{\circ}$, Sophia Kaestle ${ }^{1}$, Theresa Stüber ${ }^{1,3}$, Vincent Schwarze ${ }^{1}$, \\ Eva Gresser ${ }^{1}{ }^{(}$, Boj F. Hoppe ${ }^{1}{ }^{\circledR}$, Jan Rudolph ${ }^{1}$, Wolfgang G. Kunz ${ }^{1}{ }^{\circledR}$, Jens Ricke ${ }^{1}$ and Bastian O. Sabel ${ }^{1}$ \\ 1 Department of Radiology, University Hospital, LMU Munich, 81377 Munich, Germany; \\ nicola.fink@med.uni-muenchen.de (N.F.); Sophia.Kaestle@med.uni-muenchen.de (S.K.); \\ theresa.stueber@med.uni-muenchen.de (T.S.); vincent.schwarze@med.uni-muenchen.de (V.S.); \\ eva.gresser@med.uni-muenchen.de (E.G.); boj.hoppe@med.uni-muenchen.de (B.F.H.); \\ jan.rudolph@med.uni-muenchen.de (J.R.); wolfgang.kunz@med.uni-muenchen.de (W.G.K.); \\ jens.ricke@med.uni-muenchen.de (J.R.); bastian.sabel@med.uni-muenchen.de (B.O.S.) \\ 2 Comprehensive Pneumology Center (CPC-M), German Center for Lung Research (DZL), \\ 81377 Munich, Germany \\ 3 Chair of Statistical Learning \& Data Science, Department of Statistics, LMU Munich, 80539 Munich, Germany \\ * Correspondence: johannes.rueckel@med.uni-muenchen.de \\ + Shared first authorship.
}

check for

updates

Citation: Rueckel, J.; Fink, N.; Kaestle, S.; Stüber, T.; Schwarze, V.; Gresser, E.; Hoppe, B.F.; Rudolph, J.; Kunz, W.G.; Ricke, J.; et al. COVID-19 Pandemic and Upcoming Influenza Season-Does an Expert's Computed Tomography Assessment Differentially Identify COVID-19, Influenza and Pneumonias of Other Origin?. J. Clin. Med. 2021, 10, 84. https://doi.org/10.3390/jcm10010084

Received: 3 November 2020 Accepted: 23 December 2020 Published: 28 December 2020

Publisher's Note: MDPI stays neutral with regard to jurisdictional claims in published maps and institutional affiliations.

Copyright: () 2020 by the authors. Licensee MDPI, Basel, Switzerland. This article is an open access article distributed under the terms and conditions of the Creative Commons Attribution (CC BY) license (https: / / creativecommons.org/ licenses/by/4.0/).
Abstract: (1) Background: Time-consuming SARS-CoV-2 RT-PCR suffers from limited sensitivity in early infection stages whereas fast available chest CT can already raise COVID-19 suspicion. Nevertheless, radiologists' performance to differentiate COVID-19, especially from influenza pneumonia, is not sufficiently characterized. (2) Methods: A total of 201 pneumonia CTs were identified and divided into subgroups based on RT-PCR: 78 COVID-19 CTs, 65 influenza CTs and 62 NonCOVID-19-Non-influenza (NCNI) CTs. Three radiology experts (blinded from RT-PCR results) raised pathogen-specific suspicion (separately for COVID-19, influenza, bacterial pneumonia and fungal pneumonia) according to the following reading scores: 0 -not typical/1-possible/2-highly suspected. Diagnostic performances were calculated with RT-PCR as a reference standard. Dependencies of radiologists' pathogen suspicion scores were characterized by Pearson's Chi ${ }^{2}$ Test for Independence. (3) Results: Depending on whether the intermediate reading score 1 was considered as positive or negative, radiologists correctly classified $83-85 \%$ (vs. NCNI) / 79-82\% (vs. influenza) of COVID-19 cases (sensitivity up to $94 \%$ ). Contrarily, radiologists correctly classified only $52-56 \%$ (vs. NCNI)/50-60\% (vs. COVID-19) of influenza cases. The COVID-19 scoring was more specific than the influenza scoring compared with suspected bacterial or fungal infection. (4) Conclusions: High-accuracy COVID-19 detection by CT might expedite patient management even during the upcoming influenza season.

Keywords: COVID-19; Sars-CoV-2; influenza; pneumonia; computed tomography; radiology

\section{Introduction}

The "Severe Acute Respiratory Syndrome Coronavirus 2" (SARS-CoV-2), causing the "coronavirus disease 19" (COVID-19), rapidly spread around the world after the first cases appeared in China in December 2019 [1-3]. By 2 September 2020, a total of more than 25 million cases with confirmed COVID-19 and more than 850,000 deaths had been reported by the WHO [4]. COVID-19 usually manifests as a respiratory disease with nonspecific symptoms including fever and cough, which is clinically similar to other respiratory diseases such as influenza pneumonia [5-8]. Regarding influenza pneumonia, the WHO estimates that the annual influenza season usually causes about 3-5 million cases of critical 
disease and 290,000 to 650,000 deaths [9]. Therefore, the upcoming annual influenza season and the difficulty to clinically distinguish between different viral infections, including influenza and COVID-19, will pose new challenges to global healthcare.

The lack of clinically specific symptoms and immediately available serum markers as well as the necessity of fast patient isolation to prevent viral spread and enable an appropriate therapy require effective strategies for an accurate and immediate diagnosis [10]. The usually performed virus detection by real-time reverse transcription polymerase chain reaction (RT-PCR) remains time-consuming and with regard to SARS-CoV-2 also suffers from limited sensitivity (approx. 70\% described by some studies) [11-13]. Increasingly abundant rapid antigen tests are known to have limited sensitivities as well, e.g., with approx. $70-80 \%$ as reported by Gremmels et al. [14]. Several studies have demonstrated immediately available computed tomography (CT) of the chest to yield higher sensitivities in detecting COVID-19 compared with RT-PCR especially in the early stages of infection $[13,15]$. Nevertheless, the majority of these studies did not provide well-balanced and sufficiently large subgroups to quantify the specificity of COVID-19-related CT imaging features or did not specifically address other relevant pathogens, e.g., subgroups of pneumonias exclusively associated with influenza infection within the large group of viruses/atypical pneumonias [16-18]. Others only described pathogen-related imaging features without finally assessing the resulting radiologists' performance in accurately raising pathogen-specific suspicion $[19,20]$. In contrast to these studies, we do not describe already well-known pathogen-related CT image patterns, but ultimately quantify the resulting radiology experts' performance to differentially raise pathogen-specific suspicion with a focus on influenza A/B and SARS-CoV-2. This approach finally aims to evaluate the added diagnostic value of fast available chest $\mathrm{CT}$ in case of underlying pneumonia based on experienced radiology experts' assessment for the upcoming flu season during the COVID-19 pandemic. Hence, this might help to balance the risks of radiation exposure and efforts related to high-volume $\mathrm{CT}$ imaging with its diagnostic benefits in addition to time-consuming RT-PCR virus detection.

\section{Experimental Section}

Approval of the institutional ethics commission was obtained for this study.

\subsection{Patient Selection}

We identified 189 patients presenting from 16 March to 12 April 2020 (the first pandemic wave in Germany) in our emergency department with suspected respiratory infection who underwent RT-PCR testing for SARS-CoV-2/influenza and received chest $\mathrm{CT}$ on admission. Furthermore, we identified another 108 patients who presented from January 2018 to 7 December 2019 (before the SARS-CoV-2 outbreak in Germany) with RT-PCR-confirmed influenza infection (influenza A or influenza B) and performed chest $\mathrm{CT}$, see Figure 1. No exclusion criteria were applied. Age, gender, follow-up RT-PCRs, laboratory parameters (C-reactive protein (CRP), lactate dehydrogenase (LDH) and leucocyte counts) timely related to $C T$ acquisition ( \pm 1 day) and clinical data regarding hospitalization/intensive care unit admission/mortality were recorded. Follow-up CTs were also included. Subgroups of patients with CT-confirmed pneumonia were built according to RTPCR-based virus detection: a COVID-19 subgroup with RT-PCR positive for SARS-CoV-2, an influenza subgroup with RT-PCR positive for influenza A or B and a Non-COVID19-Non-influenza (NCNI) subgroup with RT-PCR negative for SARS-CoV-2 as well as influenza A/B. 


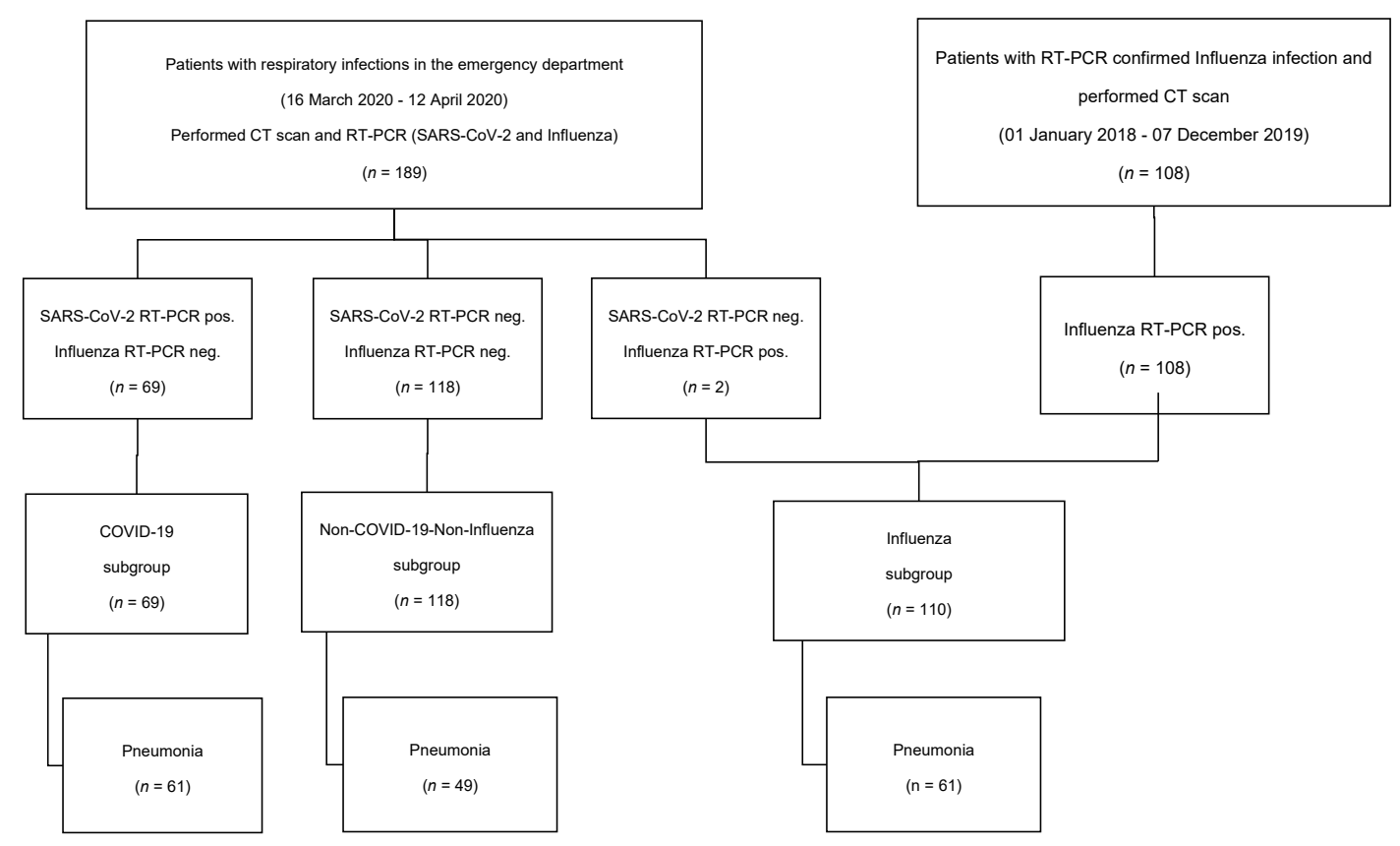

Figure 1. Flow chart illustrating patient identification. Patients presenting in the emergency department (16 March to 12 April 2020, first COVID-19 pandemic wave in Germany) were included and divided into subgroups according to RT-PCR results. Additionally, patients with confirmed influenza infection before the COVID-19 outbreak (2018/2019) were included. Patients with pneumonic CT features were divided into subgroups according to RT-PCR results for Severe Acute Respiratory Syndrome Coronavirus 2 (SARS-CoV-2) and influenza. Follow-up CTs not considered (compare Table 1).

Table 1. Subgroup characteristics.

\begin{tabular}{lr}
\hline Study cohort-CTs $[n]$ & 353 \\
Study cohort-Patients $[n]$ & 297
\end{tabular}

COVID-19 Influenza Non-COVID-19-Non-Influenza

\begin{tabular}{|c|c|c|c|}
\hline CTs $[n]$ & 86 & 132 & 135 \\
\hline No contrast media applied $[n(\%)]$ & $63(73.3 \%)$ & $98(74.2 \%)$ & $89(65.9 \%)$ \\
\hline Constrast media applied $[n(\%)]$ & $23(26.7 \%)$ & $34(25.8 \%)$ & $46(34.1 \%)$ \\
\hline Slice thickness [mean (range)] & $1.6 \mathrm{~mm}(0.625-3 \mathrm{~mm})$ & $1.6 \mathrm{~mm}(0.625-3 \mathrm{~mm})$ & $1.5 \mathrm{~mm}(0.625-3 \mathrm{~mm})$ \\
\hline \multicolumn{4}{|l|}{ Radiologist's reading } \\
\hline Pneumonia $[n(\%)]$ & $78(90.7 \%)$ & $65(49.2 \%)$ & $62(45.9 \%)$ \\
\hline Affected lung parenchyma [mean \%] & $\begin{array}{l}34.4 \pm 23.1 \% \\
* * * \text { vs. NCNI }\end{array}$ & $27.0 \pm 23.5 \%$ & $21.1 \pm 18.8 \%$ \\
\hline COVID19-Reading-Score $0[n]$ & 5 & 40 & 45 \\
\hline COVID19-Reading-Score $1[n]$ & 18 & 19 & 16 \\
\hline COVID19-Reading-Score $2[n]$ & 55 & 6 & 1 \\
\hline Influenza-Reading-Score $0[n]$ & 25 & 19 & 21 \\
\hline Influenza-Reading-Score $1[n]$ & 46 & 31 & 35 \\
\hline Influenza-Reading-Score $2[n]$ & 7 & 15 & 6 \\
\hline Bacteria-Reading-Score $0[n]$ & 64 & 28 & 18 \\
\hline Bacteria-Reading-Score $1[n]$ & 11 & 17 & 14 \\
\hline Bacteria-Reading-Score $2[n]$ & 3 & 20 & 29 \\
\hline Mycotic-Reading-Score $0[n]$ & 76 & 49 & 37 \\
\hline Mycotic-Reading-Score $1[n]$ & 0 & 18 & 17 \\
\hline Mycotic-Reading-Score $2[n]$ & 2 & 7 & 8 \\
\hline
\end{tabular}


Table 1. Cont.

\begin{tabular}{|c|c|c|c|}
\hline Patients $[n]$ & 69 & 110 & 118 \\
\hline Age $[$ mean \pm SD] & $61.3 \pm 15.9$ & $59.6 \pm 16.0$ & $61.6 \pm 18.6$ \\
\hline Male sex $[n(\%)]$ & $47(68.1 \%)$ & $58(52.7 \%)$ & $71(60.2 \%)$ \\
\hline Pneumonia $[n(\%)]$ & $61(88.4 \%)$ & $61(55.5 \%)$ & $49(41.5 \%)$ \\
\hline Age $[$ mean $\pm \mathrm{SD}]$ & $63.0 \pm 15.3$ & $58.6 \pm 18.2$ & $62.4 \pm 18.2$ \\
\hline Male sex $[n(\%)]$ & $45(73.8 \%)$ & $37(60.7 \%)$ & $34(69.4 \%)$ \\
\hline Outpatient w pneumonia $[n(\%)]$ & $1(1.6 \%)$ & $2(3.3 \%)$ & $5(10.2 \%)$ \\
\hline Hospitalized $\mathrm{w}$ pneumonia $[n(\%)]$ & $60(98.4 \%)$ & $59(96.7 \%)$ & $39(89.8 \%)$ \\
\hline ICU admission $[n(\%)]$ & $18(30.0 \%)$ & $17(27.9 \%)$ & $12(24.5 \%)$ \\
\hline Mortality $[n(\%)]$ & $4(6.7 \%)$ & $12(19.7 \%)$ & $3(6.1 \%)$ \\
\hline \multicolumn{4}{|l|}{ Lab (related to initial CT scan) } \\
\hline $\mathrm{CRP}[\mathrm{mg} / \mathrm{dL}]$ & $7.5 \pm 6.9$ & $\begin{array}{c}12.6 \pm 11.1 \\
* * \text { vs. both subgroups }\end{array}$ & $7.5 \pm 7.7$ \\
\hline Leucocytes [G/L] & $7.6 \pm 4.1$ & $7.4 \pm 7.2$ & $\begin{array}{c}10.3 \pm 4.4 \\
* * \text { vs. COVID19 } \\
\text { * vs. Influenza }\end{array}$ \\
\hline $\mathrm{LDH}$ & $386 \pm 207$ & $352 \pm 184$ & $\begin{array}{c}314 \pm 122 \\
* \text { vs. COVID19 }\end{array}$ \\
\hline
\end{tabular}

Patients presenting in the emergency unit during the first COVID-19 pandemic wave (16 March to 12 April 2020) with suspected respiratory infection who underwent thoracic CT were included. Another 108 patients presenting in 2017/2018 with influenza infection and acquired chest CT were equivalently included. Subgroups were formed based on RT-PCR results (COVID-19 vs. influenza vs. Non-COVID-19Non-influenza), subgroup characteristics as shown above. Significance levels (regarding laboratory values) are illustrated as * $p<0.05$, ${ }^{* *} p<0.01,{ }^{* * *} p<0.001$.

\subsection{Chest CT Image Acquisition and Radiologist's CT Assessment}

We included initial CT scans (related to initial presentation for the patients identified in 2020 or timely related to RT-PCR positive for influenza for the patients identified in 2018/2019) as well as possible follow-up CT scans in case of hospitalization. CT scans were performed according to local protocols as native high-resolution or contrast-enhanced CT scan in case of suspected pulmonary embolism (Somatom Force (Siemens Healthineers, Erlangen, Germany), Somatom Definition AS+ (Siemens Healthineers, Erlangen, Germany) and Optima 660 (GE Healthcare, Chalfont St Giles, Great Britain)). Diagnostic axial reconstructions were performed using a lung kernel and slice thicknesses of $1.36 \pm 0.77 \mathrm{~mm}$ (0.625-3 mm).

One board-certified radiologist and two radiology residents (with $>8 / 3 / 2$ years of experience in thoracic imaging, including recent experience during the SARS-CoV-2 pandemic wave in Germany) evaluated the CT scans by consensus. The radiology residents are considered to be well trained after having worked as radiologists on duty in one of the largest emergency department in one of the most affected hotspots in Germany during the COVID-19 outbreak; our readers are therefore representative of the radiological diagnostic performance provided to the referring clinicians. Readers were blinded to the RT-PCR results, date of CT examination and clinical and laboratory patient data.

CT images were analyzed regarding the presence of pneumonic features (yes/no), quantified according to the percentage of affected lung parenchyma (10 percentage steps used by radiologists) and, in case of pneumonia, analyzed regarding the presence of typical findings separately for COVID-19, influenza, fungal/mycotic pneumonia and bacterial pneumonia (0-not typical, 1-possible, 2-highly suspicious). According to the current literature, COVID-19 typical findings were defined as ground glass opacities (GGOs) with or without "crazy paving", consolidations and subpleural bands with a focus on the peripheral, posterior and lower lung zones usually without relevant pleural effusions or mediastinal lymphadenopathy [21-23]. Compared to COVID-19, influenza pneumonia also manifests as GGOs with or without consolidations but is more likely to have nodules, tree-in-bud signs and pleural effusion with pneumonic features distributed in a more interstitial pattern $[24,25]$. Typical CT findings in pulmonary fungal infection 
are nodules with surrounding ground glass opacities [26]. Bacterial bronchopneumonia is usually characterized by multilocular peribronchiolar patchy consolidations in a lobular pattern, e.g., caused by aspiration from the colonized trachea, whereas bacterial lobar pneumonia usually shows more geographic consolidations with a predominance of the lower lung lobes $[25,27]$. Examples of pneumonia CTs including reading scores for COVID19/influenza and the corresponding subgroup belongings are illustrated in Figure 2.
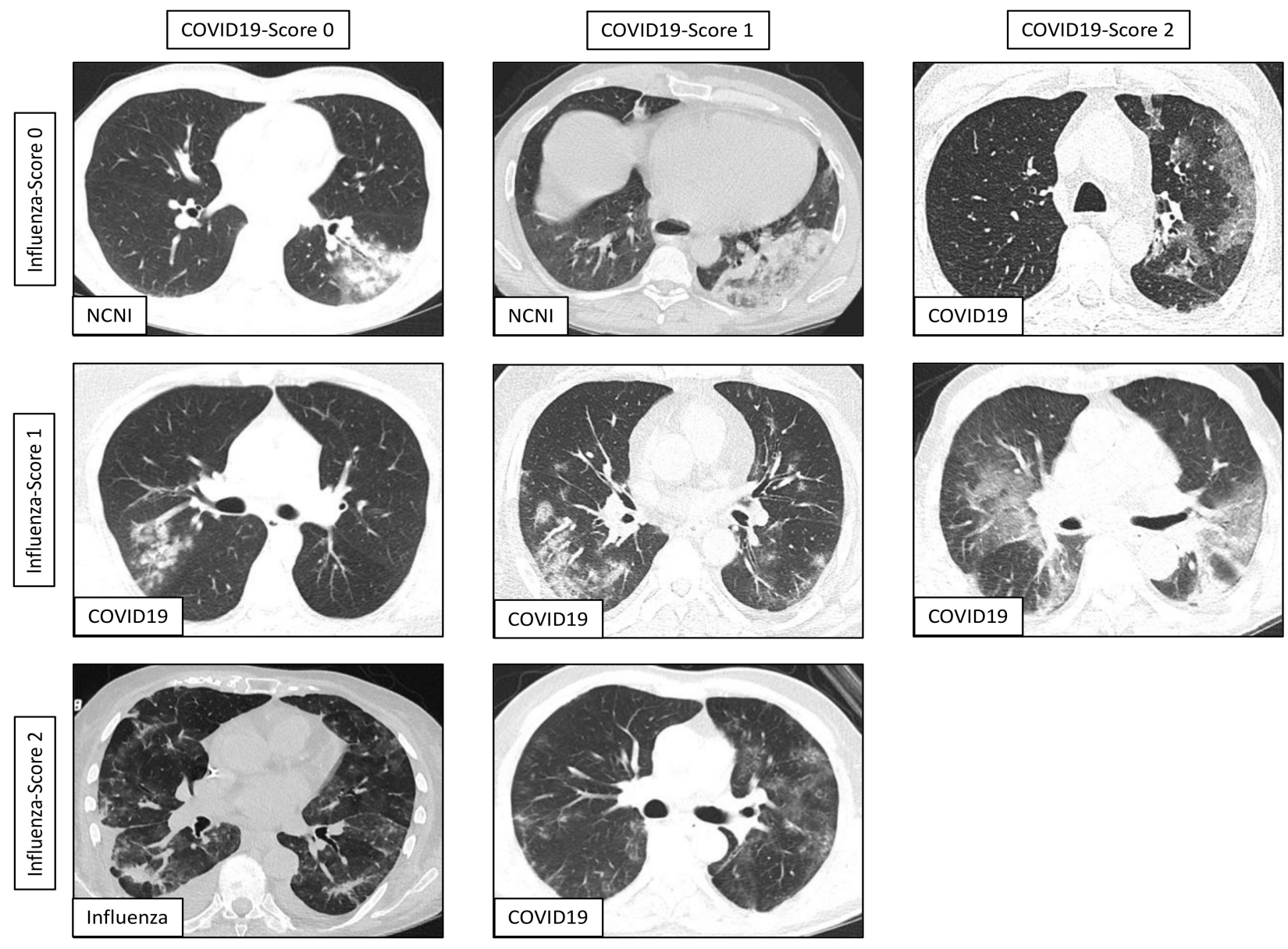

Figure 2. Representative findings from CT scans depicting pneumonia including radiologists' scoring for COVID-19 and influenza suspicion ( $3 \times 3$ matrix) as well as corresponding subgroup belongings (in-image bottom left) according to RT-PCR results. Images include typical as well as atypical features related to the subgroups, e.g., patchy consolidations without relevant ground glass opacities (GGOs) as an atypical example for COVID-19 (middle left). There was no CT radiologically classified with co-occurrent high suspicions (reading scores 2) for COVID-19 as well as influenza.

\subsection{Results Quantification and Statistical Analysis}

In order to produce binary outputs representing a "yes-or-no-decision" (necessary for diagnostic metrics calculation) with regard to the radiologists' suspicion for influenza or COVID-19 infection, the three-stage reading scores were pooled as follows (as previously established in the context of chest radiography [28,29]): Reading scores 0 and 1 were pooled and considered as negative representing a specific reading. Reading scores 1 and 2 were pooled and considered as positive and representing a sensitive reading, respectively. Diagnostic metrics (percentage of correctly classified cases, sensitivity, specificity, positive predictive value (PPV), negative predictive value (NPV), false positive rate (FPR) and false negative rate (FNR)) were calculated including the $95 \%$ confidence interval $(95 \% \mathrm{CI})$ with and without follow-up CTs for both the sensitive and specific reading setting. 
Patient characteristics of different subgroups including laboratory values were statistically compared by Student's $t$ test. Pearson's $\mathrm{Chi}^{2}$ Test for Independence was used to screen for dependencies of reading scores for different pathogen categories. Based on two-way contingency tables, this test compares different reading score combinations with their statistically expected prevalence in case of total independency. Significance levels were corrected for multiple testing using the Bonferroni method. Cohen-Friendly Association Plots graphically indicate deviations from independence of rows and columns in a two-dimensional contingency table. The discrepancy from statistical independence is quantified by Pearson Residuals. Results were graphically illustrated and statistically analyzed by R-Studio (RStudio Inc, Boston, MA, USA) and GraphPad Prism (Version 8.4.2, GraphPad, San Diego, CA, USA).

\section{Results}

According to the above-mentioned subgroup definitions, we identified 61 patients (78 CTs) with COVID-19 pneumonia, 61 patients (65 CTs) with pneumonic CT features and influenza infection and 49 patients (62 CTs) with pneumonic CT features without COVID-19 or influenza infection (NCNI) (see Figure 1 and Table 1). The proportion of patients with pneumonic CT features within the COVID-19 subgroup (88.4\%) was higher compared with the influenza (49.2\%) and NCNI (41.5\%) subgroups (see Table 1 ). The hospitalization rate in cases of confirmed pneumonia (89.8-98.4\%) and demographic data (age, gender) were similar in all subgroups (see Table 1). Patients of the influenza subgroup had significantly higher CRP levels and patients of the NCNI subgroup showed significantly higher leucocyte counts, each compared with the other subgroups (see Table 1). COVID-19 was associated with the highest percentage of affected lung parenchyma with a significant difference compared with the NCNI subgroup and no significant difference compared to the influenza subgroup (see Table 1).

The radiologists' diagnostic performance in identifying underlying COVID-19 or influenza infection in case of pneumonic CT features was characterized by separately comparing to the other two subgroups, by applying a sensitive or specific reading score pooling as described above and by including or excluding follow-up CTs (see Table 2). Representative findings from $\mathrm{CT}$ scans with corresponding reading scores and subgroup belongings are also illustrated in Figure 2.

Regarding COVID-19 pneumonia, radiologists correctly classified $80-85 \%$ of COVID19 cases separately referenced to both influenza and NCNI cases and for both the specific and sensitive reading score pooling (see Table 2). Nevertheless, as expected, the sensitive reading score pooling achieved higher sensitivities of up to $94 \%$ with associated FNRs of $6 \%$ for both subgroup comparisons but associated with a slightly higher FPR of $39 \%$ when referencing to the Influenza subgroup (vs. FPR of $27 \%$ for the comparison with the NCNI subgroup) (see Table 2). The specific reading score pooling achieved specificities of $90-98 \%$ but can be considered to be of lower clinical relevance due to FNRs of $26-30 \%$. 
Table 2. Radiologist's Diagnostic Metrics (Subgroup Analysis) for the Classification of Atypical Pneumonias according to Assumed COVID-19 or Influenza Infection.

\begin{tabular}{|c|c|c|c|c|c|c|c|c|c|c|}
\hline \multicolumn{11}{|c|}{ COVID19 vs. Non-COVID-Non-Influenza } \\
\hline $\begin{array}{l}\text { Reading Score } \\
\text { Positive for } \\
\text { COVID19 }\end{array}$ & $\begin{array}{l}\text { Follow-Up } \\
\text { CTs Included }\end{array}$ & $n$ & $\begin{array}{c}\text { Prevalence } \\
\text { COVID-19 } \\
\text { (RT-PCR) }\end{array}$ & $\begin{array}{l}\% \text { Correct } \\
\text { Classified }\end{array}$ & Sensitivity & Specificity & PPV & NPV & FPR & FNR \\
\hline $1+2$ & Yes & 140 & 0.56 & $0.84(0.78-0.90)$ & $0.94(0.86-0.98)$ & $0.73(0.60-0.82)$ & $0.81(0.73-0.89)$ & $0.90(0.82-0.98)$ & $0.27(0.17-0.38)$ & $0.06(0.01-0.12)$ \\
\hline 2 & Yes & 140 & 0.56 & $0.83(0.77-0.89)$ & $0.71(0.60-0.80)$ & $0.98(0.90-1.00)$ & $0.98(0.95-1.00)$ & $0.73(0.63-0.82)$ & $0.02(0.00-0.05)$ & $0.30(0.20-0.39)$ \\
\hline $1+2$ & No & 110 & 0.56 & $0.84(0.77-0.91)$ & $0.93(0.84-0.98)$ & $0.71(0.58-0.82)$ & $0.80(0.71-0.90)$ & $0.90(0.80-0.99)$ & $0.29(0.16-0.41)$ & $0.07(0.01-0.13)$ \\
\hline 2 & No & 110 & 0.56 & $0.85(0.78-0.91)$ & $0.74(0.61-0.83)$ & $0.98(0.88-1.00)$ & $0.98(0.94-1.00)$ & $0.75(0.64-0.86)$ & $0.02(0.00-0.06)$ & $0.26(0.16-0.37)$ \\
\hline \multicolumn{11}{|c|}{ COVID19 vs. Influenza } \\
\hline $\begin{array}{l}\text { Reading Score } \\
\text { Positive for } \\
\text { COVID19 }\end{array}$ & $\begin{array}{l}\text { Follow-Up } \\
\text { CTs Included }\end{array}$ & $n$ & $\begin{array}{l}\text { Prevalence } \\
\text { COVID-19 } \\
\text { (RT-PCR) }\end{array}$ & $\begin{array}{l}\% \text { Correct } \\
\text { Classified }\end{array}$ & Sensitivity & Specificity & PPV & NPV & FPR & FNR \\
\hline $1+2$ & Yes & 143 & 0.55 & $0.79(0.72-0.86)$ & $0.94(0.85-0.98)$ & $0.62(0.49-0.72)$ & $0.75(0.66-0.83)$ & $0.89(0.80-0.98)$ & $0.39(0.27-0.50)$ & $0.06(0.01-0.12)$ \\
\hline 2 & Yes & 143 & 0.55 & $0.80(0.73-0.86)$ & $0.71(0.60-0.80)$ & $0.91(0.81-0.96)$ & $0.90(0.83-0.98)$ & $0.72(0.62-0.82)$ & $0.09(0.02-0.16)$ & $0.30(0.20-0.39)$ \\
\hline $1+2$ & No & 122 & 0.50 & $0.80(0.72-0.87)$ & $0.93(0.84-0.98)$ & $0.66(0.53-0.76)$ & $0.73(0.63-0.83)$ & $0.91(0.82-0.99)$ & $0.34(0.23-0.46)$ & $0.07(0.01-0.13)$ \\
\hline 2 & No & 122 & 0.50 & $0.82(0.75-0.89)$ & $0.74(0.61-0.83)$ & $0.90(0.80-0.96)$ & $0.88(0.79-0.97)$ & $0.78(0.68-0.87)$ & $0.10(0.03-0.17)$ & $0.26(0.16-0.37)$ \\
\hline \multicolumn{11}{|c|}{ Influenza vs. Non-COVID19-Non-Influenza } \\
\hline $\begin{array}{l}\text { Reading Score } \\
\text { Positive for } \\
\text { Influenza }\end{array}$ & $\begin{array}{l}\text { Follow-Up } \\
\text { CTs Included }\end{array}$ & $n$ & $\begin{array}{l}\text { Prevalence } \\
\text { Influenza } \\
\text { (RT-PCR) }\end{array}$ & $\begin{array}{l}\% \text { Correct } \\
\text { Classified }\end{array}$ & Sensitivity & Specificity & PPV & NPV & FPR & FNR \\
\hline $1+2$ & Yes & 127 & 0.51 & $0.53(0.44-0.61)$ & $0.71(0.59-0.80)$ & $0.34(0.23-0.46)$ & $0.53(0.42-0.63)$ & $0.53(0.37-0.68)$ & $0.66(0.55-0.78)$ & $0.29(0.19-0.40)$ \\
\hline 2 & Yes & 127 & 0.51 & $0.56(0.47-0.65)$ & $0.23(0.15-0.35)$ & $0.90(0.80-0.96)$ & $0.71(0.52-0.91)$ & $0.53(0.43-0.62)$ & $0.10(0.03-0.17)$ & $0.77(0.67-0.87)$ \\
\hline $1+2$ & No & 110 & 0.56 & $0.54(0.44-0.63)$ & $0.69(0.56-0.79)$ & $0.38(0.23-0.49)$ & $0.57(0.46-0.68)$ & $0.47(0.31-0.64)$ & $0.65(0.53-0.78)$ & $0.31(0.20-0.42)$ \\
\hline 2 & No & 110 & 0.56 & $0.52(0.43-0.61)$ & $0.21(0.13-0.33)$ & $0.90(0.78-0.96)$ & $0.72(0.52-0.93)$ & $0.48(0.38-0.58)$ & $0.10(0.02-0.18)$ & $0.79(0.69-0.89)$ \\
\hline \multicolumn{11}{|c|}{ Influenza vs. COVID19 } \\
\hline $\begin{array}{l}\text { Reading Score } \\
\text { Positive for } \\
\text { Influenza }\end{array}$ & $\begin{array}{l}\text { Follow-Up } \\
\text { CTs Included }\end{array}$ & $N$ & $\begin{array}{l}\text { Prevalence } \\
\text { Influenza } \\
\text { (RT-PCR) }\end{array}$ & $\begin{array}{l}\% \text { Correct } \\
\text { Classified }\end{array}$ & Sensitivity & Specificity & PPV & NPV & FPR & FNR \\
\hline $1+2$ & Yes & 143 & 0.46 & $0.50(0.42-0.58)$ & $0.71(0.59-0.80)$ & $0.32(0.23-0.43)$ & $0.47(0.37-0.56)$ & $0.57(0.42-0.72)$ & $0.68(0.58-0.78)$ & $0.29(0.19-0.40)$ \\
\hline 2 & Yes & 143 & 0.46 & $0.60(0.52-0.68)$ & $0.23(0.15-0.35)$ & $0.91(0.82-0.96)$ & $0.68(0.49-0.88)$ & $0.59(0.50-0.68)$ & $0.09(0.03-0.15)$ & $0.77(0.67-0.87)$ \\
\hline $1+2$ & No & 122 & 0.50 & $0.52(0.43-0.61)$ & $0.69(0.56-0.79)$ & $0.34(0.24-0.47)$ & $0.51(0.40-0.62)$ & $0.53(0.37-0.68)$ & $0.66(0.54-0.77)$ & $0.31(0.20-0.42)$ \\
\hline 2 & No & 122 & 0.50 & $0.58(0.49-0.67)$ & $0.21(0.13-0.33)$ & $0.95(0.86-0.99)$ & $0.81(0.62-1.00)$ & $0.55(0.45-0.64)$ & $0.05(0.00-0.10)$ & $0.79(0.69-0.89)$ \\
\hline
\end{tabular}

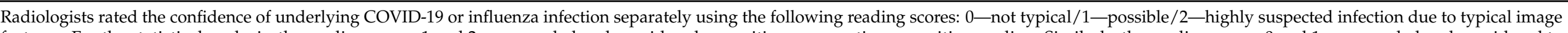

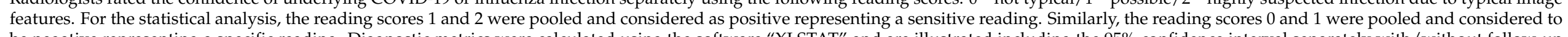

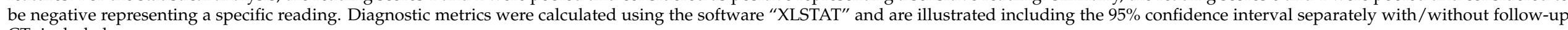
CTs included. 
Regarding pneumonias associated with influenza infection confirmed by RT-PCR, radiologists correctly classified only $50-60 \%$ of cases separately referenced to both COVID19 and NCNI cases and for both the specific and sensitive reading score pooling, see Table 2 with illustrated diagnostic metrics in detail.

The lack of radiologist's diagnostic performance in identifying pneumonias associated with influenza infection indicates much less specific associated CT imaging features. The specificity of imaging features being associated with different pathogen categories (fungal, bacterial, influenza, COVID-19) by the radiology experts was indirectly quantified by Pearson's Chi ${ }^{2}$ Test for Independence based on the applied pathogen-specific reading scores, see contingency tables and Cohen-Friendly Association Plots, plots in Figure 3. As an example, co-occurrent suspicion for COVID-19 and mycotic pneumonia was significantly underrepresented, see Figure 3A3. Similarly, any strong suspicion for bacterial pneumonia was associated with COVID-19 suspicion for significantly less cases than statistically expected, see Figure 3A2. Co-occurrent strong suspicion (score 2) for COVID-19 and influenza was statistically underrepresented, but any strong suspicion for influenza was statistically associated with an intermediate suspicion (score 1) for COVID-19, see Figure 3A1. Summing up, COVID-19 associated image features have been more specifically discriminated from bacterial and mycotic pneumonia than from pneumonic image features of patients suffering from an influenza infection, see Figure 3A1-A3 and Table 3. Furthermore, in cases of highly suspected bacterial pneumonia (score 2), a co-occurrent suspicion for a possible fungal pneumonia was also statistically significantly overrepresented, see Figure $3 \mathrm{C}$ and Table 3. Statistically significant over- or underrepresented co-suspicions for influenza/bacterial and influenza/fungal pneumonias (here: statistically independent scorings, see Table 3) have not been observed, see Figure 3B1,B2. It has to be kept in mind, that the displayed $p$-values in Figure 3 are the non-corrected ones. The corresponding statistical analysis corrected for multiple testing is illustrated in Table 3.

Table 3. Dependencies of radiologist's suspicion scores for different pathogen categories were screened by Pearson's Chi ${ }^{2}$ Test for Independence (statistics including corrections for multiple testing using the Bonferroni method).

\begin{tabular}{ccccc}
\hline \multirow{2}{*}{ Combination } & \multicolumn{2}{c}{ Pearson's Chi ${ }^{2}$ Test for Independence } & \\
& Chi $^{2}$ Statistics & df & $\boldsymbol{p}$-Value & Corr. $\boldsymbol{p}$-Value \\
\hline COVID vs. Influenza & 31.52173 & 4 & 0.000002 & 0.000014 \\
COVID vs. Bacterial & 76.11953 & 4 & 0.000000 & 0.000000 \\
COVID vs. Mycotic & 72.65716 & 4 & 0.000000 & 0.000000 \\
Influenza vs. Bacterial & 14.15284 & 4 & 0.006823 & 0.040937 \\
Influenza vs. Mycotic & 0.97985 & 4 & 0.912836 & 1.000000 \\
Bacterial vs. Mycotic & 53.03143 & 4 & 0.000000 & 0.000000 \\
\hline
\end{tabular}

The reading scores for influenza and mycotic pathogen suspicion were the only statistically independent ones; the other reading scores showed statistical signs of dependency (to discriminate positive or negative dependency (see Figure 3). 
A1
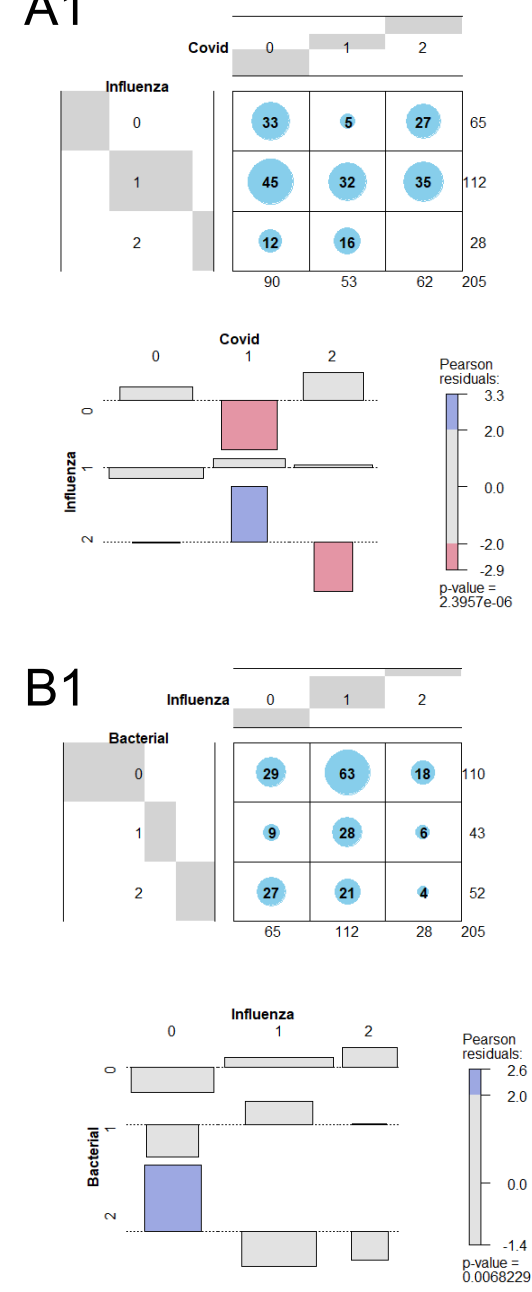

A2
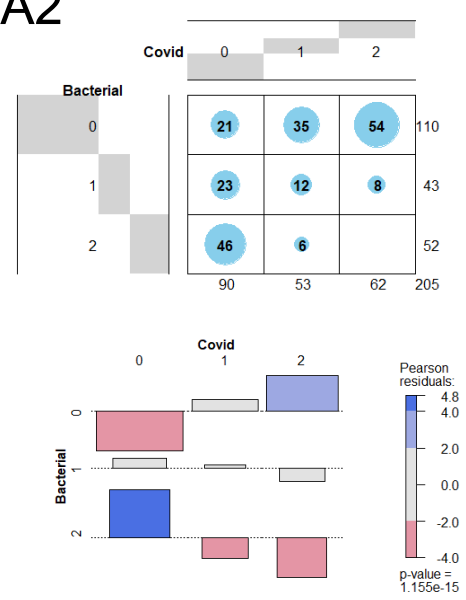

B2
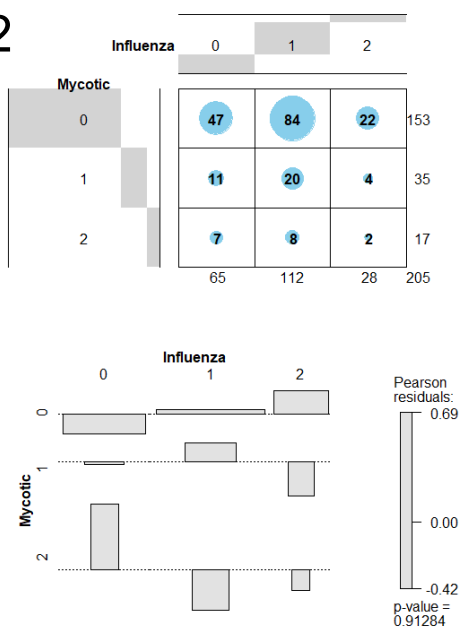

A3
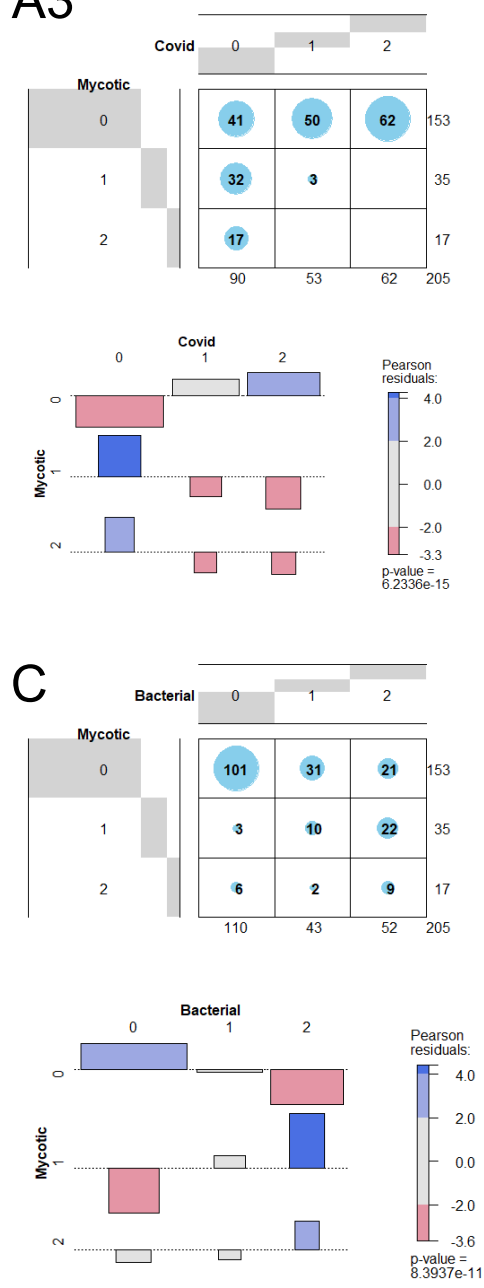

Figure 3. Dependencies of radiologists' suspicion scores for different pathogen categories were screened by Pearson's Chi ${ }^{2}$ Test for Independence (graphic illustration). Distribution of reading scores for every combination of pathogen category (influenza, COVID-19, bacterial, mycotic) are illustrated by $3 \times 3$ contingency tables. Cohen-Friendly Association Plots illustrate deviations from the statistically expected contingency table in the case of total independency. In the Cohen-Friendly Association Plot, each cell of the contingency table is represented by a rectangle that has a (signed) height proportional to its contribution to the $\mathrm{Chi}^{2}$ Statistic. Simultaneously, the area of the box is proportional to the difference in observed and expected frequencies. The rectangles in each row are positioned relative to a baseline indicating independence/no contribution to the $\mathrm{Chi}^{2}$ Statistic. If the observed frequency of a cell is greater than the expected one, the box rises above the baseline and is shaded in blue. Otherwise, the box falls below the baseline and is shaded in red. Discrepancies from the independency scenario are quantified by Pearson Residuals (PR), which can be interpreted as follows: $-2<$ PR $<2-$ no significant dependency $/-4<\mathrm{PR}<-2$ or $2<\mathrm{PR}<4$-significant dependency $/ \mathrm{PR}<-4$ or $\mathrm{PR}>4$-strong significant dependency. The displayed $p$-values are the noncorrected. Corresponding statistical analysis corrected for multiple testing by the Bonferroni method is illustrated in Table 3. Under-represented co-occurrent suspicions for mycotic/COVID19 pneumonia or bacterial/COVID-19 pneumonia indicate specific image features of COVID-19 pneumonia (A2/A3). Contrarily, over-represented co-suspicions for bacterial/mycotic pneumonia indicate partially shared image features (C).

\section{Discussion}

In a subgroup pneumonia analysis, we demonstrated the capability of fast available chest CT to accurately identify an underlying COVID-19 infection (sensitivity up to 94\%) also compared with other atypical pneumonias, especially including influenza-associated pneumonia. This performance is similar to, e.g., that reported by Bai et al. [18] for the differential detection of COVID-19 compared to other atypical pneumonias (not influenzaspecific). Additionally, this performance partially overcomes recently presented artificial 
intelligence algorithms for COVID-19, e.g., as reported for an algorithm with sensitivities of up to $84 \%$ (and accuracies of up to $90 \%$ ) by Harmon et al. (even here tested on image data that - in contrast to our study - does not equivalently also contain pneumonias of other origin) [30]. The sufficiently accurate COVID-19 detection by fast available CT might contribute to a time-efficient patient management that is hampered by well-known limitations of RT-PCR testing for SARS-CoV-2 (limited availability and accuracy similar to recently established rapid antigen tests, delay of PCR tests until the availability of results) and might be complicated by the upcoming seasonal flu. Contrarily to COVID-19 pneumonia, influenza-associated pneumonic CT features were not specific enough for a reliable identification based on chest CT imaging as separately assessed by a radiological suspicion score for influenza.

In respiratory infectious diseases, early identification of the underlying pathogens is crucial to improve individual patient management and to find an appropriate therapy [10]. In view of the currently rising number of COVID-19 cases and the upcoming seasonal flu, early diagnosis is also of great importance to enable an efficient use of healthcare resources and to prevent further viral spread. With a diagnostic performance accuracy up to $85 \%$ and sensitivity up to $94 \%$, our study identified chest CT scans to reliably distinguish COVID-19 from other infections, including influenza pneumonia. Since viral pneumonias show similar symptoms and diagnostic sensitivities of SARS-CoV-2 RT-PCR are limited [11,12], fast available chest CT can support a time-efficient identification of COVID-19 suspicion and thus enable the necessary triage of patients at an early stage. Discrepancies in CT findings and PCR results at the time of initial presentation have been described in both directions [31,32]. Within our study cohort, we observed three out of 69 patients with suspicious CT findings but timely related initial RT-PCR tests negative for SARS-CoV-2 (converted to positive in the following days), which supports the added value of CT imaging for initial diagnosis in selected cases. The other way around, there were 8 out of 69 patients with SARS-CoV-2 infection confirmed by RT-PCR without any pneumonic CT features. In contrast to COVID-19, radiologists' performance in detecting influenza pneumonia was significantly lower: In reference to COVID-19 and NCNI cases, only 50-60\% of influenza pneumonia cases were correctly identified. The discrepancy in radiological performance between COVID-19 and influenza pneumonia indicates more specific CT patterns in COVID-19 patients, which had already been observed in other studies, here with regard to several CT morphologically described image features but without any resulting radiologists' discriminative performance assessment [33]. The independency testing of the applied pathogen-specific reading scores supports this thesis also, considering radiologists' discriminative performance: A co-occurrent suspicion of COVID-19 and mycotic or bacterial pneumonia was under-represented (see Figure 3A2,A3). Furthermore, a co-occurrent strong suspicion (score 2) of COVID-19 and influenza was under-represented, while radiologists also considered a COVID-19 pneumonia (score 1) if they had a strong suspicion (score 2) for influenza as the cause of respiratory infection (see Figure 3A1). In contrast to COVID-19, the independency testing as well as diagnostic metrics reveal no diagnostic power of chest CT to identify influenza-associated pneumonia. However, it has already been reported that influenza can be detected by RT-PCR with a sensitivity range of $90.5-98.4 \%$ and a specificity range of $97.6-99.7 \%$ depending on the applied test [34-37], which is much more accurate when compared with diagnostic metrics of SARS-CoV-2 RT-PCR [13]. Therefore, in contrast to COVID-19 suspicion, an efficient triage of patients with primarily suspected influenza infection (e.g., without any suspected preceding SARS-CoV-2 contact) should be based on molecular testing methods instead of chest CT. In addition, the precise diagnostic performance of fast available chest CT scans regarding the detection of COVID-19 pneumonia as opposed to influenza becomes more important when considering the contagiousness of the pathogens: COVID-19 is particularly contagious with an estimated reproduction factor of 5.7 [38], whereas the corresponding value of seasonal influenza is estimated to be significantly lower with 1.27 [39]. This implies that when triaging patients with respiratory infections, the early isolation of COVID-19 
patients is particularly crucial to prevent a further viral spread. Immediate available chest CT might contribute to a time-efficient patient management.

Major study limitations refer to the applied reference standard solely based on virus detection by RT-PCR, whereas we were not able to provide an accurate reference standard, especially for nonviral pathogens (e.g., bronchoalveolar lavage usually not performed). In the case of COVID-19 or influenza detection, we necessarily assumed these pathogens to cause the CT-confirmed pneumonia without any chance to distinguish possible secondary co-infections. Those superinfections are much more commonly observed in the case of influenza compared with a SARS-CoV-2 infection [40-43] and might contribute to the blurred discriminativeness of radiologists' suspicion scores between influenza and bacterial infection (Figure 3B1) as well as between influenza and mycotic infection (Figure 3B2). A possible selection bias might have contributed as well; due to the population's awareness for respiratory infections being much lower in 2018/2019 than during the 2020 COVID-19 pandemic, influenza patients might have presented at a later infection stage in 2018/2019 with influenza patient selection that also already included pre-hospitalized patients. This might be the reason for more severe diseases and possible co-infections in the influenza subgroup compared with COVID-19 patients who were solely identified during initial presentation in the emergency unit. Accordingly, more specific CT image features of COVID-19 patients might also be due to an earlier infection stage and we are not able to differentially consider late stages of COVID-19 pneumonia. Nevertheless, the potential clinical added value of CT imaging is focused on initial diagnosis (usually during early infection stages) of SARS-CoV-2 infection possibly not yet detectable by RT-PCR, and even in our study cohort, early stage COVID-19 pneumonias did not show a lower percentage of affected lung parenchyma compared with influenza patients. Minor study limitations refer to the radiologists' consensus reading not allowing for inter-reader variability analysis and radiologists possibly being better trained for COVID-19 detection after having recently worked during the first local pandemic COVID-19 wave in Germany. Additionally, falsenegative RT-PCRs for SARS-CoV-2 might have altered subgroup definition, although 49 out of 120 patients (as far as possible in case of hospitalization) initially presenting in 2020 without SARS-CoV-2 detection received at least two RT-PCRs.

In conclusion, we confirmed the diagnostic power of an expert radiologist's chest CT assessment to sensitively identify COVID-19 pneumonia focused on early infection stages that were also compared with other atypical pneumonias, especially those associated with influenza infection. During the upcoming influenza season, an additional chest CT might help to rapidly identify pneumonias suspicious for SARS-CoV-2 infection and can contribute to cope with the limited accuracy and results delay of SARS-CoV-2 RT-PCR. Even increasingly abundant antigen tests might help to rapidly confirm suspected SARSCoV-2 infections, but in consideration of the limited sensitivity of rapid antigen tests, there is still an added value of chest $\mathrm{CT}$ as a rapidly available additive clinical decision tool. Contrarily to SARS-CoV-2, influenza pneumonia cannot be reliably identified by chest $\mathrm{CT}$ due to nonspecific image features. This diagnostic gap can be easily filled by RT-PCR testing, which is much more accurate for influenza than for SARS-CoV-2 detection.

Author Contributions: Conceptualization: J.R. (Johannes Rueckel), N.F. and B.O.S. Methodology: J.R. (Johannes Rueckel), N.F., T.S. and B.O.S. Formal analysis: J.R. (Johannes Rueckel) and T.S. Data curation: J.R. (Johannes Rueckel), N.F. and S.K. Writing-original draft preparation: J.R. (Johannes Rueckel) and N.F. Writing—review and editing: T.S., V.S., E.G., B.F.H., J.R. (Jan Rudolph), W.G.K., J.R. (Jens Ricke), B.O.S. Visualization: J.R. (Johannes Rueckel), N.F. and T.S. Supervision: J.R. (Jens Ricke), and B.O.S. Project administration: B.O.S. All authors have read and agreed to the published version of the manuscript.

Funding: This research received no external funding.

Institutional Review Board Statement: The study was conducted according to the guidelines of the Declaration of Helsinki, and approved by the institutional ethics commission of the Medical Faculty, LMU Munich (approval number 18-399, date of approval April 7th 2020). 
Informed Consent Statement: Patient consent was waived due to observational study character and anyway performed and clinically indicated CT imaging.

Conflicts of Interest: The authors declare no conflict of interest.

\section{References}

1. World Health Organization. Novel Coronovirus-China. Available online: https://www.who.int/csr/don/12-january-2020 -novel-coronavirus-china/en/ (accessed on 3 September 2020).

2. World Health Organization. Rolling Updates on Coronavirus Disease (COVID-19). Available online: https:/ /www.who.int/ emergencies/diseases/novel-coronavirus-2019/events-as-they-happen (accessed on 3 September 2020).

3. Coronaviridae Study Group of the International Committee on Taxonomy of Viruses. The species Severe acute respiratory syndrome-related coronavirus: Classifying 2019-nCoV and naming it SARS-CoV-2. Nat. Microbiol. 2020, 5, 536-544. [CrossRef] [PubMed]

4. WHO Coronavirus Disease (COVID-19) Dashboard. Available online: https:/ / covid19.who.int (accessed on 3 September 2020)

5. Chen, N.; Zhou, M.; Dong, X.; Qu, J.; Gong, F.; Han, Y.; Qiu, Y.; Wang, J.; Liu, Y.; Wei, Y.; et al. Epidemiological and clinical characteristics of 99 cases of 2019 novel coronavirus pneumonia in Wuhan, China: A descriptive study. Lancet 2020, 395, 507-513. [CrossRef]

6. Yang, X.; Yu, Y.; Xu, J.; Shu, H.; Liu, H.; Wu, Y.; Wu, Y.; Zhang, L.; Yu, Z.; Fang, M.; et al. Clinical course and outcomes of critically ill patients with SARS-CoV-2 pneumonia in Wuhan, China: A single-centered, retrospective, observational study. Lancet Respir. Med. 2020, 8, 475-481. [CrossRef]

7. Tian, S.; Hu, N.; Lou, J.; Chen, K.; Kang, X.; Xiang, Z.; Chen, H.; Wang, D.; Liu, N.; Liu, D.; et al. Characteristics of COVID-19 infection in Beijing. J. Infect. 2020, 80, 401-406. [CrossRef]

8. Xu, X.-W.; Wu, X.-X.; Jiang, X.-G.; Xu, K.-J.; Ying, L.-J.; Ma, C.-L.; Li, S.-B.; Wang, H.-Y.; Zhang, S.; Gao, H.-N.; et al. Clinical findings in a group of patients infected with the 2019 novel coronavirus (SARS-Cov-2) outside of Wuhan, China: Retrospective case series. BMJ 2020, 368, m606. [CrossRef]

9. World Health Organization. Influenza (Seasonal). Available online: https://www.who.int/news-room/fact-sheets/detail/ influenza-(seasonal) (accessed on 3 September 2020).

10. Zhang, N.; Wang, L.; Deng, X.; Liang, R.; Su, M.; He, C.; Hu, L.; Su, Y.; Ren, J.; Yu, F.; et al. Recent advances in the detection of respiratory virus infection in humans. J. Med. Virol. 2020, 92, 408-417. [CrossRef]

11. Long, C.; Xu, H.; Shen, Q.; Zhang, X.; Fan, B.; Wang, C.; Zeng, B.; Li, Z.; Li, X.; Li, H.; et al. Diagnosis of the Coronavirus disease (COVID-19): rRT-PCR or CT? Eur. J. Radiol. 2020, 126, 108961. [CrossRef]

12. Sawano, T.; Kotera, Y.; Ozaki, A.; Murayama, A.; Tanimoto, T.; Sah, R.; Wang, J. Underestimation of COVID-19 cases in Japan: An analysis of RT-PCR testing for COVID-19 among 47 prefectures in Japan. QJM Int. J. Med. 2020, 113, 551-555. [CrossRef]

13. Fang, Y.; Zhang, H.; Xie, J.; Lin, M.; Ying, L.; Pang, P.; Ji, W. Sensitivity of Chest CT for COVID-19: Comparison to RT-PCR. Radiology 2020, 296, E115-E117. [CrossRef]

14. Ai, T.; Yang, Z.; Hou, H.; Zhan, C.; Chen, C.; Lv, W.; Tao, Q.; Sun, Z.; Xia, L. Correlation of Chest CT and RT-PCR Testing in Coronavirus Disease 2019 (COVID-19) in China: A Report of 1014 Cases. Radiology 2020. Available online: https:/ /www.ncbi. nlm.nih.gov/pmc/articles/PMC7233399/ (accessed on 3 September 2020).

15. Li, Y.; Xia, L. Coronavirus Disease 2019 (COVID-19): Role of Chest CT in Diagnosis and Management. Am. J. Roentgenol. 2020, 214, 1280-1286. [CrossRef]

16. Wang, H.; Wei, R.; Rao, G.; Zhu, J.; Song, B. Characteristic CT findings distinguishing 2019 novel coronavirus disease (COVID-19) from influenza pneumonia. Eur. Radiol. 2020, 30, 4910-4917. [CrossRef] [PubMed]

17. Altmayer, S.; Zanon, M.; Pacini, G.S.; Watte, G.; Barros, M.C.; Mohammed, T.-L.; Verma, N.; Marchiori, E.; Hochhegger, B. Comparison of the Computed Tomography Findings in COVID-19 and Other Viral Pneumonia in Immunocompetent Adults: A Systematic Review and Meta-Analysis. SSRN Electron. J. 2020, 1-12. [CrossRef]

18. Simpson, S.; Kay, F.U.; Abbara, S.; Bhalla, S.; Chung, J.H.; Chung, M.; Henry, T.S.; Kanne, J.P.; Kligerman, S.; Ko, J.P.; et al. Radiological Society of North America Expert Consensus Statement on Reporting Chest CT Findings Related to COVID-19. Endorsed by the Society of Thoracic Radiology, the American College of Radiology, and RSNA-Secondary Publication. J. Thorac. Imaging 2020, 35, 219-227. [CrossRef]

19. Li, K.; Wu, J.; Wu, F.; Guo, D.; Chen, L.; Fang, Z.; Li, C. The Clinical and Chest CT Features Associated With Severe and Critical COVID-19 Pneumonia. Investig. Radiol. 2020, 55, 327-331. [CrossRef] [PubMed]

20. Ye, Z.; Zhang, Y.; Wang, Y.; Huang, Z.; Song, B. Chest CT manifestations of new coronavirus disease 2019 (COVID-19): A pictorial review. Eur. Radiol. 2020, 30, 4381-4389. [CrossRef] [PubMed]

21. Liu, M.; Zeng, W.; Wen, Y.; Zheng, Y.; Lv, F.; Xiao, K. COVID-19 pneumonia: CT findings of 122 patients and differentiation from influenza pneumonia. Eur. Radiol. 2020, 1-7. [CrossRef]

22. Reynolds, J.H.; McDonald, G.; Alton, H.; Gordon, S.B. Pneumonia in the immunocompetent patient. Br. J. Radiol. 2010, 83, 998-1009. [CrossRef]

23. Demirkazik, F.B.; Akin, A.; Uzun, O.; Akpinar, M.G.; Ariyürek, M.O. CT findings in immunocompromised patients with pulmonary infections. Diagn. Interv. Radiol. 2008, 14, 75-82. 
24. Tarver, R.D.; Teague, S.D.; Heitkamp, D.E.; Conces, D.J. Radiology of Community-Acquired Pneumonia. Radiol. Clin. N. Am. 2005, 43, 497-512. [CrossRef]

25. Rueckel, J.; Kunz, W.G.; Hoppe, B.F.; Patzig, M.; Notohamiprodjo, M.; Meinel, F.G.; Cyran, C.C.; Ingrisch, M.; Ricke, J.; Sabel, B.O. Artificial Intelligence Algorithm Detecting Lung Infection in Supine Chest Radiographs of Critically Ill Patients With a Diagnostic Accuracy Similar to Board-Certified Radiologists. Crit. Care Med. 2020, 48, e574-e583. [CrossRef]

26. Kunz, W.; Patzig, M.; Crispin, A.; Stahl, R.; Reiser, M.F.; Notohamiprodjo, M. The Value of Supine Chest X-Ray in the Diagnosis of Pneumonia in the Basal Lung Zones. Acad. Radiol. 2018, 25, 1252-1256. [CrossRef] [PubMed]

27. Zhang, J.; Ding, D.; Huang, X.; Zhang, J.; Chen, D.; Fu, P.; Shi, Y.; Xu, W.; Tao, Z. Differentiation of COVID-19 from seasonal influenza: A multicenter comparative study. J. Med. Virol. 2020. [CrossRef] [PubMed]

28. Maignan, M.; Viglino, D.; Hablot, M.; Termoz Masson, N.; Lebeugle, A.; Collomb Muret, R.; Makele, P.M.; Guglielmetti, V.; Morand, P.; Lupo, J.; et al. Diagnostic accuracy of a rapid RT-PCR assay for point-of-care detection of influenza A/B virus at emergency department admission: A prospective evaluation during the 2017/2018 influenza season. PLoS ONE 2019, 14, e0216308. [CrossRef] [PubMed]

29. Dugas, A.F.; Valsamakis, A.; Gaydos, C.A.; Forman, M.; Hardick, J.; Kidambi, P.; Amin, S.; Gupta, A.; Rothman, R.E. Evaluation of the Xpert Flu Rapid PCR Assay in High-Risk Emergency Department Patients. J. Clin. Microbiol. 2014, 52, 4353-4355. [CrossRef] [PubMed]

30. Antoniol, S.; Fidouh, N.; Ghazali, A.; Ichou, H.; Bouzid, D.; Kenway, P.; Choquet, C.; Visseaux, B.; Casalino, E.; The Emergency Department Study Group on Respiratory Viruses. Diagnostic performances of the Xpert ${ }^{\circledR}$ Flu PCR test and the OSOM ${ }^{\circledR}$ immunochromatographic rapid test for influenza A and B virus among adult patients in the Emergency Department. J. Clin. Virol. 2018, 99-100, 5-9. [CrossRef] [PubMed]

31. Valentin, T.; Kieslinger, P.; Stelzl, E.; Santner, B.I.; Groselj-Strele, A.; Kessler, H.H.; Tiran, B. Prospective evaluation of three rapid molecular tests for seasonal influenza in patients presenting at an emergency unit. J. Clin. Virol. 2019, 111, 29-32. [CrossRef]

32. Sanche, S.; Lin, Y.T.; Xu, C.; Romero-Severson, E.; Hengartner, N.; Ke, R. High Contagiousness and Rapid Spread of Severe Acute Respiratory Syndrome Coronavirus 2. Emerg. Infect. Dis. 2020, 26, 1470-1477. [CrossRef]

33. Biggerstaff, M.; Cauchemez, S.; Reed, C.; Gambhir, M.; Finelli, L. Estimates of the reproduction number for seasonal, pandemic, and zoonotic influenza: A systematic review of the literature. BMC Infect Dis. 2014, 14, 480. [CrossRef]

34. McCullers, J.A. The co-pathogenesis of influenza viruses with bacteria in the lung. Nat. Rev. Genet. 2014, 12, 252-262. [CrossRef]

35. Garcia-Vidal, C.; Sanjuan, G.; Moreno-García, E.; Puerta-Alcalde, P.; Garcia-Pouton, N.; Chumbita, M.; Fernandez-Pittol, M.; Pitart, C.; Inciarte, A.; Bodro, M.; et al. Incidence of co-infections and superinfections in hospitalised patients with COVID-19: A retrospective cohort study. Clin. Microbiol. Infect. 2020, 27, 83-88. [CrossRef]

36. Hughes, S.; Troise, O.; Donaldson, H.; Mughal, N.; Moore, L. Bacterial and fungal coinfection among hospitalized patients with COVID-19: A retrospective cohort study in a UK secondary-care setting. Clin. Microbiol. Infect. 2020, 26, 1395-1399. [CrossRef] [PubMed]

37. Robinson, K.M.; Kolls, J.K.; Alcorn, J.F. The immunology of influenza virus-associated bacterial pneumonia. Curr. Opin. Immunol. 2015, 34, 59-67. [CrossRef] [PubMed]

38. Harmon, S.A.; Sanford, T.H.; Xu, S.; Turkbey, E.B.; Roth, H.; Xu, Z.; Yang, D.; Myronenko, A.; Anderson, V.; Amalou, A.; et al. Artificial intelligence for the detection of COVID-19 pneumonia on chest CT using multinational datasets. Nat. Commun. 2020, 11, 1-7. [CrossRef] [PubMed]

39. Xie, X.; Zhong, Z.; Zhao, W.; Zheng, C.; Wang, F.; Liu, J. Chest CT for Typical Coronavirus Disease 2019 (COVID-19) Pneumonia: Relationship to Negative RT-PCR Testing. Radiology 2020, 296, E41-E45. [CrossRef]

40. Gremmels, H.; Winkel, B.M.; Schuurman, R.; Rosingh, A.; Rigter, N.A.; Rodriguez, O.; Ubijaan, J.; Wensing, A.M.J.; Bonten, M.J.; Hofstra, L.M. Real-life validation of the PanbioTM COVID-19 antigen rapid test (Abbott) in community-dwelling subjects with symptoms of potential SARS-CoV-2 infection. EClinicalMedicine 2020. Available online: https:/ / www.thelancet.com/journals/ eclinm/article/PIIS2589-5370(20)30421-1/abstract (accessed on 13 December 2020).

41. Bernheim, A.; Mei, X.; Huang, M.; Yang, Y.; Fayad, Z.; Zhang, N.; Diao, K.; Lin, B.; Zhu, X.; Li, K.; et al. Chest CT Findings in Coronavirus Disease-19 (COVID-19): Relationship to Duration of Infection. Radiology 2020, 295, 200463. [CrossRef]

42. Lin, L.; Fu, G.; Chen, S.; Tao, J.; Qian, A.; Yang, Y.; Wang, M. CT Manifestations of Coronavirus Disease (COVID-19) Pneumonia and Influenza Virus Pneumonia: A Comparative Study. Am. J. Roentgenol. 2020, 216, 1-9. [CrossRef]

43. Bai, H.X.; Hsieh, B.; Xiong, Z.; Halsey, K.; Choi, J.W.; Tran, T.M.L.; Pan, I.; Shi, L.-B.; Wang, D.-C.; Mei, J.; et al. Performance of Radiologists in Differentiating COVID-19 from Non-COVID-19 Viral Pneumonia at Chest CT. Radiology 2020, 296, 200823. [CrossRef] 